\title{
O CUIDADO EM HEIDEGGER COMO APROFUNDAMENTO DA INTENCIONALIDADE HUSSERLIANA
}

CARE IN HEIDEGGER AS A DEEPENING OF HUSSERLIAN INTENTIONALITY

\author{
ANa CARla De ABreu SiqueIRA ${ }^{1}$ \\ Universidade Federal do Ceará (UFC/FUNCAP) - Brasil \\ carladeabreus@gmail.com
}

\begin{abstract}
RESUMO: O presente artigo tem como objetivo analisar a intencionalidade e sua modificação na filosofia de Martin Heidegger em relação ao pensamento de Edmund Husserl. Realizamos uma pesquisa que inicia na teoria husserliana da intencionalidade como um elemento fundamental da consciência. Em seguida, apresentamos como a fenomenologia heideggeriana se transformou com o apoio da hermenêutica e como ela se distanciou das teses fenomenológicas de seu professor. Por último, mostramos qual a definição que Heidegger atribui à intencionalidade e como a estrutura ontológica chamada cuidado é um aprofundamento deste conceito, o que lhe atribui uma rica significação diante das teorias modernas que ainda estavam bastante evidentes na filosofia de Husserl.
\end{abstract}

PALAVRAS-CHAVE: Consciência. Cuidado. Heidegger. Husserl. Intencionalidade.

ABSTRACT: The present paper has as its purpose to analyze intentionality, and its modification, in the philosophy of Martin Heidegger in relation to Edmund Husserl's thought. We conduct a research that begins with Husserl's theory of intentionality as a fundamental element of consciousness. Then, we present how Heideggerian phenomenology was transformed with the support from hermeneutics and how Heidegger distanced himself from the phenomenological theses of his professor. Finally, we show the definition that Heidegger attributes to intentionality and how the ontological structure called care is a deepening of this concept, which gives it a rich meaning in the face of modern theories that were still quite evident in Husserl's philosophy.

KEYWORDS: Consciousness. Care. Heidegger. Husserl. Intentionality.

\section{INTRODUÇÃO}

Fundamento do método fenomenológico, o conceito de intencionalidade é carregado de dificuldades específicas. Uma delas reside na sua própria fluidez, uma vez que ele se transforma desde o período medieval até a hermenêutica de Martin Heidegger, passando pelo lugar essencial que ocupou na fenomenologia de Edmund Husserl. Enquanto este sustentou que intencionalidade e consciência são termos equivalentes, seu aluno mais célebre identifica a intencionalidade com a estrutura do cuidado (Sorge) e coloca o Dasein como elemento principal da fenomenologia. Sem nos aprofundarmos em seus antecedentes medievais, mencionamos brevemente a importância e o rigor inerentes ao conceito tal como

\footnotetext{
${ }^{1}$ Doutora em Filosofia pela Universidade Federal do Ceará (UFC/FUNCAP).
} 
foi apropriado pelo filósofo e psicólogo Franz Brentano, de quem Husserl foi discípulo.

No sentido medieval, a intenção (intentio) era a categoria que exprimia a tentativa de possuirmos algo que fazia parte da consciência e, através dela, o sujeito imperfeito buscava alcançar a concretização de sua potência pela apreensão total do fenômeno ao qual se dirigia. No comentário de Michelle Cabral: "A intenção deseja possuir o objeto, deseja concluir o que em potência já está na consciência, é uma constante busca pelo télos da intenção." (CABRAL, 2010, p. 122). Tal capacidade atribuía um aspecto moral à intenção, pois buscava realizar fins com perfeição. O conceito ressurgiu em Brentano a partir da sua tentativa de diferenciar fenômenos físicos - aqueles que possuem extensão - e fenômenos psíquicos representações, ideias e emoções. Na fenomenologia, essa característica de não possuir extensão é chamada de inexistência intencional.

Segundo André Leclerc, "o prefixo 'in-' é um prefixo de localização (existir em) e não de negação." (LECLERC, 2015, p. 2). Como exemplo, ele explica que, em uma fotografia, a pessoa in-existe: vemos seus traços, seu sorriso e seu corpo, mas ela não está concretamente ali na imagem diante da nossa presença. Mesmo assim, podemos nos dirigir a esse "objeto". Brentano já havia afirmado que a consciência é uma atualidade, um ato psicológico que tem como conteúdo algum objeto transcendental ou imaginado. Os objetos nunca seriam criações da subjetividade, mas somente nivelados por ela e, portanto, nós lhes atribuímos significados. Todo pensamento se refere a um objeto pensado, todo amor a um objeto amado, todo julgamento a um objeto julgado, toda lembrança a um objeto lembrado (HUSSERL, 2006, p.190).

Com um entendimento próximo ao que encontramos na interpretação de Husserl, a referência intencional é apresentada por Brentano "como a propriedade da consciência de ser consciência de algo, a capacidade de se dirigir para um objeto ou, em outras palavras, de ter um conteúdo mental que seja representado, julgado, amado ou odiado." (MARIANI, 2017, p. 19). Todavia, a teoria de Brentano recebeu críticas justamente porque ainda estava bastante conectada à psicologia. Emanuele Mariani comenta que, apesar de central, a intencionalidade jamais foi uma categoria fixa durante a tradição e assim explica sua evolução:

Centro de gravitação e, ao mesmo tempo, condição de possibilidade da própria fenomenologia, a intencionalidade se atesta explicitamente em todo o seu alcance desde a primeira reflexão de Husserl, que herda e transforma um conceito de origem brentaniana; um conceito que o próprio Brentano recupera da tradição escolástica através de uma leitura de Aristóteles destinada a reativar o sentido fundamental, isto é, fundador, da experiência [...] para o dizer em termos ainda mais abrangentes, como a imposição de um sentido que atribuímos ao mundo onde vivemos; como aquilo que permite que as coisas nos apareçam de uma forma ou de outra, e aquilo a partir do qual as "próprias coisas" prescrevem para a consciência a multiplicidade dos seus modos de doação. (MARIANI, 2017, p. 18-9). 
Husserl deixa de lado as significações morais e psicológicas para situar o conceito como elemento fundamental do processo de conhecimento e, em consequência, para auxiliar a fenomenologia a alcançar o estatuto de ciência rigorosa. É certo que a consciência alcança uma posição basilar na sua filosofia e se torna o principal critério para todo saber (ZAHAVI, 2015, p.67). Mas isso só é possível na medida em que a sua relação com a intencionalidade lhe dá um caráter de transcendental, ou seja, é capaz de sustentar a evidência por meio de um retorno ao fenômeno. A fim de compreendermos a intencionalidade, exploramos inicialmente a concepção husserliana. De antemão, esse passo requer entendermos a tarefa da consciência e da redução, inserindo esses conceitos no quadro do pensamento de Husserl.

Em seguida, confrontamos as ideias de Heidegger com a fenomenologia de Husserl e no que sua própria fenomenologia evolui em relação àquela proposta por seu professor. Isso acontece nomeadamente por meio do desenvolvimento da hermenêutica e sua identificação com uma ontologia. Assim, mostramos aspectos usuais de um conceito do qual fazemos uso cotidiano, mas cuja relevância passa despercebida. Embora a intenção não seja restringir a fenomenologia husserliana a uma obra específica, a escolha do texto Ideias para uma fenomenologia pura $e$ para uma filosofia fenomenológica (1913) é justificada pela crítica do próprio autor e de alguns intérpretes a Ideias $I$ no que diz respeito ao desenvolvimento e à exploração do método (ZAHAVI, 2015, p. 65).

Por fim, exploramos o cuidado, uma constituição ontológica da existência humana. Apesar de ter um sentido unitário (PASQUALIN, 2016, p.39), é articulada pelas várias estruturas próprias ao Dasein - tais como a compreensão e a afetividade, como veremos adiante. Além disso, visto que o Dasein é um ente inacabado e que tem à sua disposição inúmeras possibilidades, ele é sempre abertura ao que ainda precisa cumprir e escolher, aos outros e aos eventos do mundo. O cuidado, que é o modo de ser de quem está sempre na preocupação e no envolvimento, é em si mesmo intencional e permite a renovação da intencionalidade na filosofia heideggeriana.

\section{CONSCIÊNCIA E INTENCIONALIDADE NA FENOMENOLOGIA DE HUSSERL}

Nas primeiras linhas de Ideias I, Husserl define a fenomenologia pura como "uma ciência essencialmente nova, distante do pensar natural em virtude de sua peculiaridade de princípio [...]. Ela se denomina uma ciência de "fenômenos" (HUSSERL, 2006, p.25). Trata-se de um método descritivo dos fenômenos e das experiências a partir das vivências do sujeito. Segundo Edith Stein (2018, p. 217) existe um falso entendimento de que a fenomenologia se ocupa da aparência; de certo, seu interesse reside nas essencialidades. Apoiado no mesmo interesse, Husserl fala de uma ciência eidética cuja tarefa é explicitar a própria essência de um indivíduo e dos fenômenos (HUSSERL, 2006, p.28). E uma vez que ela não investiga fatos nem busca resultados mensuráveis, ele afirma que: 
[...] a fenomenologia tem por essência de reivindicar o direito de ser filosofia 'primeira' e de oferecer os meios para toda crítica da razão que se possa almejar; e que, por isso, ela requer a mais completa ausência de pressupostos e absoluta evidência reflexiva sobre si mesma. Sua essência própria é a realização da mais perfeita clareza sobre sua própria essência e, com isso, também sobre os princípios de seu método. (HUSSERL, 2006, p. 144).

Sua pretensão teria sido radicalizar a pergunta sobre os conceitos fundamentais para formular uma ciência rigorosa que evitasse as falhas da psicologia e da tradição filosófica. Contudo, aquilo que a define é muito mais do que essa capacidade de voltar-se para os fenômenos. A exclusividade deste método diante daqueles adotados por outras ciências reside na descrição dos fenômenos a partir da consciência, cuja característica primordial é encontrar a verdade sem sofrer influências de qualquer relativismo, tais como o psicologismo ou o historicismo (STEIN, 2018, p. 217). Assim, os elementos que formaram a base para o projeto husserliano foram: a ênfase na subjetividade e suas vivências; a consciência que presentifica o objeto através da redução fenomenológica; a noção de que o mundo e toda forma de transcendência dependem do sujeito.

Enquanto a subjetividade é imanente e depende apenas de si, o mundo e todos os seus elementos carecem do sujeito (ZAHAVI, 2015, p. 71). Por essa razão, qualquer reflexão sobre a intencionalidade só se pode realizar a partir do entendimento prévio desses termos. Para Husserl, a consciência é formada por atos diversos, tais como percepção, imaginação, valoração, volição etc., além de se constituir por vivências que orientam o sujeito em direção aos fenômenos. Ela é essencial na medida em que dá sentido aos vividos e possibilita todas as experiências antes mesmo de nos darmos conta disso (MARIANI, 2017, p. 27).

Antes de falarmos que temos consciência de algo, existe uma definição mais ampla que resume o próprio existir por meio do fluxo de sensações e da inteligibilidade. Em outras palavras, estamos dotados de uma vivência anterior a toda vivência intencional, a saber, o viver na sua originalidade e o qual Descartes traduziu na ideia de que o pensamento é uma obviedade ${ }^{2}$. Devido a esse caráter, o eu puro se assemelha bastante ao cogito cartesiano. Todavia, a diferença fundamental entre este eu puro e o cogito é que, para Husserl, não basta que o homem tenha a consciência de si: nós temos consciência de algo. E o que marca essa ligação entre a dimensão subjetiva e os objetos é a intencionalidade.

\footnotetext{
${ }^{2}$ Através da dúvida e ao colocar em suspeita aquilo que fora previamente considerado como uma certeza adquirida, seja no sono ou na vigília, Descartes analisa o modo como os objetos se manifestam para o sujeito e como o sujeito percebe a si mesmo. Ele nos inspira a abandonarmos todas as opiniões que estejam marcadas por qualquer traço de dúvida até que encontremos algo certo, um ponto fixo que se transforme no solo de onde surgem opiniões seguras. Mas a partir do momento em que o sujeito projeta qualquer possibilidade da dúvida, já está exercitando o pensamento - atributo que o acompanha e determina em qualquer ocasião. A primeira certeza e a evidência resultaram no cogito, segundo o qual no instante em que o sujeito questiona, duvida, compara informações e escolhe, ele pensa. Assim, Descartes admite que o homem é "uma coisa que pensa, isto é, um espírito, um entendimento ou uma razão” (DESCARTES, 1987, p. 94).
} 
De acordo com Husserl, a intencionalidade é a propriedade dos vividos e do cogito, mas também o principal tema da fenomenologia. Ele defende que: "A intencionalidade é aquilo que caracteriza a consciência no sentido forte, e que justifica ao mesmo tempo designar todo o fluxo de vivido como fluxo de consciência e como unidade de uma única consciência." (HUSSERL, 2006, p. 190). Para elucidar como essa categoria se tornou indispensável para a doação de sentido, Husserl apresenta a redução fenomenológica como atitude que suspende ou coloca entre parênteses o mundo natural e toda objetividade. Seu propósito é dar prioridade aos atos da consciência e sua capacidade de apreensão, uma vez que a consciência é apodítica.

Com a epoché, ele afirma a existência do mundo e seus elementos, porém, sua validade depende de noções estabelecidas pelo sujeito, ao invés de se apoiar nos juízos elaborados pelas ciências que se referem ao mundo através de experimentos. Daí o uso da famosa expressão "para as coisas mesmas" (zu den Sachen selbst): o que se deve pôr fora de circuito são os fatos para que a essência dos fenômenos fique em evidência (HUSSERL, 2006, p. 83-4). Husserl se concentra no eu puro e mostra que a consciência intencional é a região do ser, definindo-se também como a condição de possibilidade do verdadeiro conhecimento. Essa nova orientação é conhecida como orientação fenomenológica.

Pôr o mundo em parênteses é descrevê-lo como aparece na consciência e voltar-se para os fenômenos. A orientação fenomenológica traz com ela objetividades, o que faz com que a consciência seja denominada de consciência transcendental (HUSSERL, 2006, p. 83). Isso significa que ela é sempre consciência de algo: coisas materiais, obras de arte, objetos que estão na imaginação ou na memória, valores, sensações, corpos, lugares, pois os fenômenos aparecem de forma direta na percepção ou apenas potencialmente. Como diz o pensador, "as coisas pairam diante de nós em caracterizações distintas, como coisas reais, possíveis, fictícias etc." (HUSSERL, 2006, p. 88). Se a consciência se volta para os objetos percebidos na realidade e nas lembranças, na imaginação e nas possibilidades, significa que perceber é sempre perceber algo, lembrar é lembrar algo, se importar é se importar com algo, pensar é pensar em algo.

Em outros termos, todos os atos intencionais se voltam para algum objeto correlativo, ainda que não exista uma correspondência concreta entre o processo psíquico e o objeto em questão. No caso da imaginação, qualquer um pode pensar em entidades que não foram comprovadas na realidade, tais como um unicórnio ou sereias. Desse modo, podemos afirmar que há sempre um nexo entre a consciência e algum objeto ou uma vivência. Ela é consciência de algo em todos os atos: não amamos algo aleatoriamente, mas algo desejável; sempre pensamos em algo; estamos sempre a julgar um objeto correlativo e assim por diante. Nossos atos de consciência direcionados a uma obra de arte, por exemplo, sempre estão acompanhados por um julgamento estético.

Husserl conclui que perceber é um comportamento distinto de conduzir o eu pensante fisicamente a um objeto. A percepção é um modo de agir orientador em todas as nossas ações cotidianas. Portanto, todos os comportamentos, atos, experiências e percepções são intencionais; ou seja, sempre está pressuposta a 
correlação do sujeito com algum objeto. A intencionalidade é um ato da consciência em sintonia com a objetividade a fim de abrigar todo sentido e assim, a intenção se volta para os dados da consciência (intencionalidade imanente) e para os objetos que ultrapassam a consciência (intencionalidade transcendental).

Fica evidente que o mundo e seus objetos existem, mas eles passam pela mente e, na medida em que afetam o sujeito, estão necessariamente em correlação com a consciência pura. Essa postura gera um modelo específico de idealismo, chamado de idealismo transcendental. Dizer que o objeto é real significa impedir sua transformação em algo imanente a consciências específicas e de caráter pessoal. Husserl não pretendia "converter todo o mundo em ilusão subjetiva e se lançar nos braços de um 'idealismo berkeliano'” (HUSSERL, 2006, p. 129). A intencionalidade jamais é uma categoria estritamente idealista, pois ela precisa da relação com o objeto para trabalhar e isso faz com que sempre exista uma ligação necessária entre seres humanos e o mundo. Sobre as descobertas da orientação ao mundo, Husserl afirma que:

\begin{abstract}
$\mathrm{Na}$ orientação natural não se podia ver mesmo outra coisa que o mundo natural. Enquanto não fora reconhecida a possibilidade de orientação fenomenológica e não fora desenvolvido o método de trazer à apreensão originária as objetividades que com ela surgem, o mundo fenomenológico tinha de permanecer um mundo desconhecido e até quase impressentido. (HUSSERL, 2006, p. 845).
\end{abstract}

Se eu afirmo que experimento o mundo mesmo a partir da minha consciência e das minhas possibilidades ${ }^{3}$, já estou afirmando que existe uma realidade a ser experimentada. Logo, a realidade do mundo é um dado ontológico e me faz escapar de qualquer idealismo radical. Mas o mundo e seus fenômenos só têm validade ao tomarmos a consciência como ponto de partida. A redução é a atitude que põe entre parênteses as teses sobre qualquer objetividade que faz parte do mundo natural disposto ao sujeito. Ao mesmo tempo, ela permite reconhecer a experiência transcendental, uma vez que os objetos são tomados como aparecem para a consciência e, portanto, como parte da realidade que experienciamos. Porém, não podemos confundir essa postura de suspensão com a eliminação da realidade devido a uma mudança radical onde a consciência, "que tinha permanecido até aí velada, é descoberta como a condição subjetiva da possibilidade de toda manifestação." (ZAHAVI, 2015, p. 70).

Isso significa que os fenômenos se mostram na consciência autônoma e até mesmo o mundo é reduzido a um objeto para o sujeito por meio de uma atitude reflexiva. Em consequência, assumimos um compromisso pelo qual realizamos um novo encontro com o mundo e com a realidade, transformando-os em fenômenos puros. Enquanto a atitude natural extrai propriedades do mundo e seus elementos, a fenomenologia é descritiva e conhece a coisa mesma depurada dos ideais

\footnotetext{
${ }^{3}$ Nas Meditações cartesianas (1931), toda intencionalidade possui um horizonte formado por diversas posições de percepção. Ou seja, os significados daí apreendidos podem se modificar de acordo com meu ponto de vista e isso me oferece várias possibilidades. (HUSSERL, 1960, p. 44).
} 
trazidos pelas ciências. O conhecimento se realiza pela reflexão, a qual consiste em todo ato de apreender e analisar um fluxo de vividos, incluindo aí a própria consciência. E a intencionalidade é a condição do acesso às coisas mesmas, é a estrutura que nos transforma em transcendentes e impede que fiquemos enclausurados em nossa interioridade.

O que marca essa capacidade de transcender? Segundo Husserl, a percepção é o modo de acesso imediato ao objeto real. Como exemplo, ele acredita que, quando eu considero uma árvore, em vez de se tratar exatamente de uma representação minha, ela é o próprio objeto da percepção que tem um efeito causal sobre mim. De maneira semelhante, se imagino um unicórnio, também realizo um ato intencional porque um unicórnio é um objeto transcendente que só tem significado para mim no momento em que tomo consciência dele. Quando o objeto está ausente e até mesmo é algo absurdo, notamos que a intenção é independente da existência concreta de objetos. Como diz Husserl, a "coisa percebida pode existir sem que seja percebida, sem que nem mesmo se tenha potencialmente consciência dela" (HUSSERL, 2006, p. 98).

Logo, não estamos diante de um idealismo clássico, pois o objeto na sua forma física nem sempre é percebido e ainda continua a existir independente da percepção subjetiva. Mesmo assim, Husserl colocou o sujeito transcendental como o suporte de todo saber e então, a intencionalidade se transformou na estrutura sem a qual nossos processos mentais seriam vazios de sentido. Os processos mentais, denominados de vividos, são necessariamente intencionais e dependem de duas estruturas: noese e noema. Respectivamente, esses termos indicam o ato ou vivência intencional e o seu objeto correlativo que está além ou fora do ato.

Husserl demonstra essa teoria de apuração do vivido através da postura de estar diante de uma árvore em flor: se eu olho para a árvore de acordo com a orientação natural, posso afirmar que estou diante de algo real e a percepção que me permite apreendê-la é um estado psíquico que faz parte de mim. Nesse caso, haveria uma árvore efetiva e aquela criada pela consciência. Por sua vez, na orientação fenomenológica, a relação entre o ato de perceber e o percebido (a própria árvore) é conservada após a redução. Se o seu tronco é derrubado, ela continua sendo o mesmo objeto experimentado pela minha consciência após a suspensão dos juízos. Em vez de ser criação da mente, um objeto solto ou resultado de alguma alucinação, a macieira é a coisa mesma e a percepção é a vivência originária que me permite tomar conhecimento da árvore ${ }^{4}$.

Com esse exemplo, Husserl mostra que a redução e a apuração dos vividos escapam de toda espécie de ilusão que faz o olhar humano esquecer os detalhes e riquezas pertencentes ao mundo real. Assim, noese e noema constituem o pensar e o pensado, o amar e o amado, o desejar e o desejado, o julgar e o julgado. Diante dessas elucidações, é possível concordar que a intencionalidade é central

\footnotetext{
4 "A árvore pura e simples, a coisa na natureza, é tudo menos esse percebido de árvore como tal, que, como sentido perceptivo, pertence inseparavelmente à percepção. A árvore pura e simples pode pegar fogo, pode ser dissolvida em seus elementos químicos etc. Mas o sentido - o sentido desta percepção, que é algo necessariamente inerente à essência dela - não pode pegar fogo, não possui elementos químicos, nem forças, nem qualidades reais" (HUSSERL, 2006, p. 206).
} 
para a radicalização do conhecimento. De fato, a fenomenologia husserliana trouxe ganhos relevantes e poderíamos trazê-los para nossas experiências: colocamos à mostra nossas operações fundamentais e prestamos atenção às coisas mesmas, ou seja, aos fenômenos para os quais geralmente nos esquecemos de dar muita atenção na vida cotidiana.

De acordo com Cabral, o pensador "defende que somente através de tal mudança de foco, poder-se-á abrir acesso inaugural ao solo fenomenológico de investigação, no qual as próprias questões se radicalizam e assumem novos contornos de sentido" (CABRAL, 2010, p. 137). Dessa forma, podemos entender a relação entre um ato (por exemplo, o perceber), o objeto intencional (o percebido) e nosso comportamento nesta relação (ZAHAVI, 2015, p. 75). E pela suspensão da atitude natural que tomamos diante do mundo e dos objetos, descobrimos em nós mesmos novas formas de teorias a partir da relação com os fenômenos, ao invés de exclusivamente partirmos de pressupostos oferecidos pelas ciências positivistas ou pelas informações que chegam até nós com uma frequência cada vez mais ampla.

Porém, como determinar alguma condição de verdade pela consciência, se algo pode variar de acordo com o contexto histórico e nossas situações de mundo? A depender dessas variações hermenêuticas, algo pode ser temido por uns e desejado por outros, ser conhecido por uns e incompreensível aos outros. É certo que a intersubjetividade aparece como um elemento importante para não cairmos em um idealismo tradicional, pois este mundo que suspendemos é também um mundo compartilhado. Além disso, pode-se dizer que, como eu tenho um corpo, sou capaz de ter experiências que identificam o outro como uma corporeidade e, portanto, enquanto um sujeito transcendental. Husserl deixou de fora das suas reflexões a condição histórica e a temporalidade que guiam o processo de conhecimento, enquanto Heidegger desenvolveu essa questão a partir de uma fenomenologia hermenêutica e colocou o Dasein no lugar privilegiado anteriormente ocupado pela consciência.

\section{HEIDEGGER E A APROXIMAÇÃO ENTRE FENOMENOLOGIA E HERMENÊUTICA}

No breve texto Meu caminho para a fenomenologia (1963), Heidegger mescla filosofia e biografia para explicar o desenvolvimento do método fenomenológico sob uma perspectiva que se identifica com a hermenêutica e a ontologia. Embora com uma compreensão inicial limitada do tema e sem saber ao certo o que lhe fascinava (HEIDEGGER, 2009, p. 86), o jovem Heidegger se afastou da teologia e persistiu nos estudos da fenomenologia em busca de possíveis respostas para as lacunas que teriam sido deixadas pela tradição moderna. Interessavam-lhe o "ver fenomenológico", ou seja, a aplicação do método aos problemas urgentes nascidos na metafísica e, de maneira particular, as investigações de Aristóteles e sobre a filosofia aristotélica em torno do conceito de ente.

O contato entre Heidegger e Brentano foi essencial para a construção de sua fenomenologia, assim como foi decisiva a relação que desenvolveu com 
Husserl. Ele despertou para seus estudos filosóficos por meio da dissertação de Brentano, intitulada Sobre o significado múltiplo do ente segundo Aristóteles (1862). Segundo Franco Volpi, a metafísica aristotélica possivelmente já abrigava uma unidade do ser a partir da qual os entes se manifestavam de múltiplas formas e, "como a indagação de Brentano põe em evidência, o ente se diz de múltiplos modos" (VOLPI, 2013, p. 44). Apesar do rompimento com a tradição transcendental, as teorias heideggerianas certamente foram beneficiadas pelo pensamento husserliano, criticado por seu aluno devido às semelhanças mantidas com a filosofia cartesiana. Com isso, ele desenvolveu ideias próprias e modificadas em relação ao que foi exposto por Husserl e Brentano.

Para entendermos o que Heidegger quis dizer com o termo fenomenologia, partimos dos dois conceitos componentes da palavra, fenômeno e logos. A palavra fenômeno significa "o-que-se-mostra-em-si-mesmo, o manifesto" (HEIDEGGER, 2012, p. 103). Essa revelação acontece sem possíveis modificações, uma vez que o Dasein não faz representações e projeções estritamente subjetivas sobre qualquer fenômeno, na medida em que isso retiraria sua condição fundamental de permanecer acessível em seu modo genuíno de ser. O termo фaıvó $\mu \varepsilon v o v$, em sentido mais amplo e original, designava o que se mostra. Dentro desse sentido, o significado privativo de fenômeno é aquilo que parece ser e para o qual muitas vezes nosso autor usa o nome de aparência.

Ele afirma que fenômeno "é sempre somente o que constitui ser, mas ser é cada vez ser de ente e, assim, para que o ser possa ser posto-em-liberdade, é preciso então que o ente ele mesmo se apresente corretamente" (HEIDEGGER, 2012, p. 125). Porém, o ser geralmente está oculto e também existe a multiplicidade do aparecimento dos entes. Heidegger converteu o ser na questão fundamental de Ser e tempo (1927), mas também foi relevante questionar o discurso construído sobre os fenômenos. Assim, ele investigou a palavra logos, pois seus significados comuns - razão, enunciado, conceito, fundamento e juízo - se modificaram bastante na tradição filosófica. Para ele, a definição mais aproximada de logos seria fala ou discurso (Rede).

Em vez de estar limitado a uma ligação entre imagem e som ou de servir como uma ponte de concordância, "o discorrer (o fazer-ver) tem o caráter do falar, da proferição vocal em palavras" (HEIDEGGER, 2012, p. 115). Sua tarefa é revelar algo como algo através das palavras e permitir o acesso às coisas mesmas. Para a

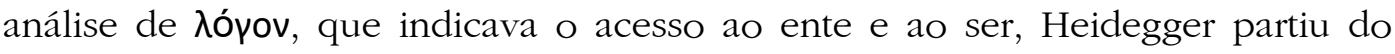
sentido fundamental do verbo $\lambda \dot{\gamma} \boldsymbol{\varepsilon} \iota v$ do qual o termo fora substantivado. A ideia que subjaz a esse verbo "significa dizer e falar" e se aproxima do termo alemão legen, "colher, recolher, escolher, o latim legere, no sentido de apanhar e juntar" (HEIDEGGER, 2006, p. 184). Quem faz uma colheita, precisa reunir os frutos e fazer aparecer, manifestar, revelar, deixar-ser.

Mas quando algo permanece encoberto, o acesso ao ente é limitado ou a coisa em questão é proposta de maneira diferente daquilo que ela realmente é, os conceitos e proposições articulados no discurso deixam de cumprir a tarefa primordial da fala. Essa reflexão heideggeriana sobre a verdade antecede as teorias 
desenvolvidas no parágrafo 44 de Ser e tempo, no qual ele discute a verdade como aletheia ou desvelamento. Isso não quer dizer que, por ser verdadeiro ou falso, o discurso seja capaz de determinar o que é verdade ou falsidade. A própria ideia de que o fenômeno é aquilo que se mostra pressupõe uma semelhança com o desvelamento, com a tarefa de deixar fazer ver os entes. A partir da composição dos termos fenômeno e logos está dado que:

O termo "fenomenologia" exprime uma máxima que pode ser assim formulada: "às coisas elas mesmas!" [zu den Sachen selbst!], em oposição a todas as construções que flutuam no ar, aos achados fortuitos, à assunção de conceitos só em aparência demonstrados, às perguntas só aparentemente feitas e que são transmitidas com frequência ao longo das gerações como "problemas". (HEIDEGGER, 2012, p. 101).

O método faz ver o que se mostra e serve para falarmos daquilo tal como aparece, a fim de irmos além das aparências. No lugar de uma ciência rigorosa com um objeto concreto e específico, portanto, o método se transforma em um caminho de acesso e investigação. Voltar-se para as coisas mesmas é interrogar como elas se manifestam e quais os seus modos de ser. Nas palavras de Irene Borges-Duarte, o método fenomenológico entrou nas investigações heideggerianas por 'ter sido capaz de tematizar a questão da 'via de acesso' ao objeto: a problemática de 'como' se constitui o sentido de objeto, na medida em que este 'Como' é inerente ao próprio sentido" (BORGES-DUARTE, 2003, p. 93). Diante disso, a fenomenologia é reconhecida em uma nova condição, a saber, enquanto um caminho de pensamento e com uma pretensão de orientação.

Heidegger teria admitido que tudo o que se mostra é recebido por algum ponto de vista, o qual existe justamente a partir da familiaridade que cultivamos com os fenômenos e o próprio mundo. Para ele, a posição que adotamos "é ela mesma algo histórico, ou seja, inseparável do ser-aí [...], ninguém é em-si quimérico e fora do tempo" (HEIDEGGER, 2011b, p. 89). Caberá a cada um reavaliar se as teses utilizadas são consideradas adequadas ou insuficientes à proposta de investigação que está em curso. Tal exercício de desconstrução permite chegarmos aos fundamentos dos temas investigados e atingirmos aquilo que está encoberto: o ser dos entes. Assim, o método fenomenológico é caracterizado pela desconstrução, isto é, um passo para trás que tem por objetivo se aproximar do significado originário e elementar dos conceitos tradicionais.

E justamente ao buscar libertar o horizonte de acesso ao ser, a fenomenologia é ontologia, cujo desenvolvimento depende de um exercício constante de interpretação. As condições de possibilidade de interpretação dos fenômenos se realizam porque o ser-aí coloca a si mesmo e o ser em geral como temas de pesquisa antes de compreender os entes. Essa preocupação com o ser com o ser em geral, mas também com o próprio ser de quem levanta essa questão e com o ser dos entes - colocou Heidegger diante de um novo processo. A hermenêutica da facticidade é a autointerpretação que realizamos sobre nós mesmos e "só é possível como a explicação do Dasein mesmo, o tipo de ente ao qual a compreensão pertence” (HEIDEGGER, 1979, p. 356). 
Segundo Heidegger, interpretar é expressar teorias sobre as descobertas adquiridas em determinado contexto e elaborar as "possibilidades projetadas" (HEIDEGGER, 2012, p. 421) no entendimento prévio. Para compreendermos o ente em seu modo de ser, também devemos reconhecer que as coisas que se mostram não são estritamente avaliadas naquilo que está imediato, mas também na possibilidade de desvelar algum sentido encoberto. Heidegger propõe superarmos o rigor da cientificidade, o paradigma da subjetividade pura e a epoché. Nesse caso, a fenomenologia heideggeriana evita a redução fenomenológica: ela não reduz a atualidade dos entes e a noção de mundo à condição de elementos da consciência, pois só apreendemos os entes a partir do nosso comportamento no mundo cotidiano, compartilhado e significativo.

Se suspendermos as teses sobre o mundo e tomarmos seus objetos como produtos da consciência, a realidade histórica será dispensada de julgamento. Por sua vez, quando Heidegger defende a postura de voltar às coisas mesmas, ele quer dizer que as referências para conhecer estão na própria história e na situação fática na qual estamos inevitavelmente inseridos. O filósofo coloca a condição de serno-mundo como paradigma fundamental para o conhecimento e assim, a estrutura da compreensão (Verstehen) ganha um significado primordial. Porém, o Dasein só compreende o ser a partir de si mesmo e só se compreende caso já possua uma compreensão prévia do ser. Seu primado ôntico é se diferenciar ontologicamente dos outros entes, visto que ele tem diversas possibilidades de existência e relações, além de sua capacidade de perguntar por seu próprio ser e pelo ser dos demais entes.

Participar do círculo hermenêutico 5 é superar a fundamentação na consciência e qualquer ideal de um a priori. Afinal, todos nós somos históricos e cultivamos expectativas de sentido. A fenomenologia se identifica com a hermenêutica, pois cada um só é capaz de lidar com os entes e conhecê-los na sua estrutura fundamental enquanto se abre à composição do seu mundo e das coisas mesmas, sem se limitar às representações. Com a fenomenologia hermenêutica, a compreensão jamais se torna uma análise vazia ou uma busca radical pela posse de algum conhecimento absoluto. E se a consciência é sempre consciência de algo que se apresenta na sua originalidade, podemos construir algum discurso acerca do modo de ser do fenômeno.

Heidegger reconhece que fenomenologia não é ciência rigorosa ou doutrina, mas uma "possibilidade de pensamento" (HEIDEGGER, 2009, p. 93), um caminho que nos conduz para as coisas mesmas. Com a retomada do método fenomenológico em Prolegomena zur Geschichte des Zeitbegriffs (1925) e depois

\footnotetext{
${ }^{5}$ Em Ser e tempo, Heidegger explica o círculo hermenêutico: "Ter de determinar primeiramente um ente em seu ser e, sobre esse fundamento, querer fazer a pergunta pelo ser, que é isto senão andar em círculo? Já não se "pressupõe" na elaboração da pergunta aquilo que só a resposta deve trazer? [...] O "ser" foi sem dúvida "pressuposto" até agora em toda ontologia, mas não como conceito disponível - não como que é buscado como tal. O "pressupor" o ser tem o caráter de uma vista prévia do ser, a partir da qual o ente já-dado é provisoriamente articulado em seu ser. Essa vista dirigida ao ser provém do mediano entendimento-do-ser em que já nos movemos sempre e que pertence afinal à constituição essencial do Dasein ele mesmo." (HEIDEGGER, 2012, p. 4749).
} 
em Ser e tempo, ele traz a novidade de que, no lugar da consciência, o Dasein é o elemento principal para a fenomenologia, pois é o único ente que está a todo instante em busca de construir um saber acerca de si mesmo, dos seus semelhantes, dos entes circundantes e do sentido do ser - embora a tarefa de conceituar o ser nunca se concretize. O ser-no-mundo é o ente que tem consciência de algo, que manipula instrumentos, faz ciência e pensa o sentido do ser. Por essa razão, o viver humano foi incorporado à própria intencionalidade.

\section{A INIENCIONALIDADE ENQUANTO CUIDADO E O SALTO da CONSCIÊNCIA AO DASEIN}

Para explicar a intencionalidade, Heidegger se direciona ao próprio objeto de estudo e transforma sua investigação em um exemplo de análise fenomenológica. A concepção heideggeriana de fenomenologia é identificada com a própria ontologia; e esta, por sua vez, foi projetada como ontologia fundamental porque busca apreender o significado do ser e examinar seus fundamentos (HEIDEGGER, 2012, p. 99). Segundo Heidegger, é impossível existir diferença entre ontologia e fenomenologia. Em outros termos, significa apreender as coisas mesmas como se dão de maneira originária em vez de defini-las enquanto objetos da subjetividade. A base sólida para irmos às coisas mesmas jamais é confundida com uma autonomia da consciência, pois todo "ver fenomenológico" também implica uma situação histórica e variados pressupostos.

Se houvesse projeções puramente pessoais sobre qualquer fenômeno, eles perderiam a condição fundamental de se manifestarem como as coisas mesmas. Ao mesmo tempo, qualquer ente tem a capacidade de se mostrar em diferentes perfis. Essa multiplicidade do aparecimento dos entes motivou o desenvolvimento estrutural da filosofia de Heidegger e também a sua retomada da fenomenologia. Sua tentativa é perguntar sobre o sentido do ser: o que é isto, que permite que as coisas sejam? Qual é nosso ser? E "se o ente é expresso em múltiplos significados, qual será, então, o determinante significado fundamental? O que quer dizer ser?" (HEIDEGGER, 2009, p. 85).

$\mathrm{O}$ acesso às coisas mesmas se realiza, tal como vimos na fenomenologia husserliana, pelo trabalho da intencionalidade. Porém, na fenomenologia heideggeriana esse processo acontece no fazer cotidiano. Antes ligado profundamente à consciência, o termo ganha relevo na vida concreta sem perder seu caráter ontológico de nos pertencer. A intencionalidade é ontológica, indelével e "não é uma propriedade, a qual seria concebida da percepção e a ela pertencer em alguns casos, mas ela é como percepção usualmente intencional, independente de o percebido estar diante na realidade ou não" (HEIDEGGER, 1979, p. 40). Minha percepção nem sempre se dirige a algo concreto e, mesmo que eu me direcione a algum objeto concreto, nem sempre se trata de um ente que se integrará corporalmente a mim.

Por exemplo, posso me situar diante de uma ponte (HEIDEGGER, 1979, p. 41), mas posso somente falar sobre a ponte ou resgatá-la na memória. O filósofo alemão chama esse ato intencional de Leermeinen (HEIDEGGER, 1979, p. 54), uma espécie de objeto vazio de conteúdo corpóreo diante de mim ou que não se pode 
dar por si mesmo. Assim, apesar do rompimento com o projeto de Husserl, o qual seria mais uma continuidade da filosofia cartesiana, Heidegger mantém a intencionalidade como uma estrutura fundamental para as nossas experiências de conhecimento. Todo ato de percepção é intencional, quer o objeto exista concretamente, quer seja um fruto de imaginação ou alucinação.

O filósofo ilustra o caso de estar caminhando em uma floresta e avistar um homem; ao se aproximar, ele percebe que o objeto diante dele é uma árvore (HEIDEGGER, 1979, p. 38). Portanto, a intencionalidade simplesmente está atuando, embora essa percepção direta o tenha colocado em contato com um objeto intencional que, por sua vez, mostrou-se ilusório. No lugar de uma propriedade física, o que marca o objeto intencionado - o noema na terminologia husserliana - é a capacidade deste ser amado, julgado, desejado, etc. Em vez de atribuir propriedades criadas por um sujeito particular, Heidegger acredita que o fenômeno pertence a um fluxo de experiências e ao mundo que é impossível suspender. Dessa forma, saber qual o conteúdo intencional e como ele está inserido em nosso campo de sentido é essencial em toda orientação fenomenológica.

A grande contribuição da tese heideggeriana da intencionalidade é não promover qualquer separação entre os atos da consciência e a dimensão fática da existência, já que o Dasein é um ente histórico, um ser-no-mundo com os outros e em algum contexto de experiências. Jamais experimentamos os fenômenos suspendendo o mundo e suas teses, mas sempre em determinada situação hermenêutica e em algum tempo específico. Heidegger fala da intencionalidade sem fundamentá-la na consciência e suspende o âmbito teórico para se concentrar nas experiências concretas:

Os comportamentos da vida são chamados de atos: percepção, julgamento, amor, ódio... O que ato significa aqui? Não atividade, processo, ou algum tipo de poder. Não, ato significa simplesmente relação intencional. Atos se referem às experiências vividas que têm o caráter de intencionalidade. (HEIDEGGER, 1979, p. 36).

Podemos dizer que a intencionalidade precisava de uma estrutura que destacasse nossos comportamentos práticos, baseando-se na perspectiva de realizações concretas no mundo. Ao criticar a ideia de um sujeito pensante e apresentar o Dasein ou ser-aí, Heidegger também expõe a existência em suas tarefas, nas ocupações e nos encontros com os outros. Para se referir ao ente que nós somos em uma condição prática, ele recorre ao cuidado. De acordo com Borges-Duarte (2010, p. 117), essa palavra resgata o sentido "do latim cogitare, pensar. Na forma transitiva, 'cuidar' é pensar: atender a, reflectir sobre - e, por isso, interessar-se por, tratar de, preocupar-se por, ter cautela com.”

O cuidado é uma estrutura fundamentalmente ontológica dos seres humanos e significa um comportamento mais amplo do que colocar o outro, o ente ou até mesmo alguma situação específica sob uma supervisão zelosa. Heidegger destaca que o cuidado pertence a toda escolha, postura e experiência humanas, designando "simplesmente o ser do Dasein." (HEIDEGGER, 1979, p. 
406). Na proporção em que possui as características existenciais de ser-já-em um mundo, ser-junto às coisas e ser-com os outros, o modo de ser da existência está permeado por responsabilidades, comprometimento, dedicação e preocupação. Somente o ser-no-mundo é capaz de apresentar motivos e razões para suas escolhas, o que implica atribuir importância aos seus projetos (CROWELL, 2012).

Por isso, diz-se que o cuidado está presente em todas as situações de convivência, embora não permita ao Dasein se colocar especificamente no lugar do outro; afinal, Heidegger não elaborou uma filosofia moral. O cuidado é inseparável da vida fática e faz parte da sua presença no mundo. Sempre que pensa e age, cada um é capaz de levar em consideração o modo de ser dos seus semelhantes em uma postura de dedicação. Para falar da cura, Heidegger se inspirou na fábula do cuidado ${ }^{6}$. Segundo explica, o cuidado moldou uma matéria a partir da terra (húmus) e então lhe conferiu um espírito a partir de Júpiter, considerado o maior dos deuses. A fábula determina que o mesmo cuidado que moldou o homem é aquele que o sustenta em toda a sua vida. Após sua morte, o corpo e o espírito retornarão aos elementos que os geraram; porém, enquanto há vida, também há cuidado.

Neste incessável estado de solicitude, o ser humano se direciona aos objetos e eventos para compreender o mundo. Produzir algo, fazer ciência, criar uma obra de arte e todas as nossas ações se sustentam em alguma descoberta prévia e interessada, um envolvimento afetivo ${ }^{7}$. Na leitura de Chiara Pasqualin, o que define o cuidado é:

[...] a imediata abertura ou exposição afetiva do ser-aí ao dado fenomenal originário, isto é, ao fato de que algo é e que o seu ser nos afeta. Antes de indicar a relação hermenêutico-interpretativa da existência com o horizonte fenomenal, o cuidado indica o fato de que o ser-aí se encontra passivamente exposto ao âmbito do ser pelo medium da afetividade. (PASQUALIN, 2016, p. 50).

Tudo o que queremos realizar está pressuposto a partir de uma ausência, de uma necessidade ou do reconhecimento daquilo que nos satisfaz (HEIDEGGER, 2012, p. 543). E em qualquer ocasião na qual o Dasein se direciona a algo, ele adota a postura de querer algo, fazer algo, lidar com algo, amar algo, pensar em algo: o cuidado acontece em função de algo e, portanto, é essencialmente intencional. Essa relação é possível na medida em que o cuidado também se refere a algo e, assim como a intencionalidade, o cuidar vai além da dimensão concreta formada por nossas relações cotidianas, pela dedicação aos outros e pelo lidar com os utensílios, a natureza e os demais entes.

\footnotetext{
${ }^{6}$ No parágrafo 31 de Prolegomena zur Geschichte des Zeitbegriffs, Heidegger atribui a Agostinho e outros autores as origens do conceito. A fábula do cuidado também é apresentada e discutida no parágrafo 42 de Ser e tempo.

${ }^{7}$ A afetividade (Befindlichkeit), substantivação do verbo sich befinden, significa "se encontrar" e, por isso, permite que o existente humano seja afetado por eventos que se advêm sobre ele nos aspectos físico e afetivo. Tal condição permite a qualquer um se encontrar em determinado estado de ânimo e compreensivo. O conceito abriga aquilo que experimentamos no cotidiano como uma forma particular de sentir, chamada de tonalidade afetiva ou humor (Stimmung).
} 
Cuidar também significa um compromisso com as variadas expressões humanas (tais como a arte, a cultura, as ciências e o pensamento) e seus modos de ser. Em resumo, os entes recebem significados e são experimentados a partir de algum interesse despertado pelos encontros que acontecem na vida cotidiana. A reflexão heideggeriana sobre o cuidado nos indica uma dimensão prática do mundo, no qual o acesso às coisas mesmas vai além do âmbito de orientação subjetiva e teórica, para também se realizar na esfera das coisas presentes e das experiências que compartilhamos uns com os outros. Heidegger diz que o existente humano nunca percebe algo meramente, senão para se orientar no mundo e "para pavimentar o caminho no lidar com algo" (HEIDEGGER, 1979, p. $30)$.

Sob essa perspectiva, pode-se dizer que cuidado é intencionalidade, pois fundamenta a direção que a vida humana segue tanto nos propósitos pessoais como nas relações e ocupações que fazem parte do mundo compartilhado. Além disso, o cuidado nunca se reduz ao si mesmo porque nenhuma existência jamais alcança um estado diferenciado diante dos outros. Ex-istir é se projetar para fora da consciência e se integrar ao mundo. Isso significa que estamos inclinados a ter um pensamento do outro, compartilhamos experiências e entendemos o outro em seu modo de ser. E significa, principalmente, que Heidegger se contrapõe ao cogito cartesiano e à consciência husserliana, já que não há mais qualquer fundamentação do saber no eu puro nem os objetos do mundo são definidos como produtos da consciência. Assim, Heidegger torna vida e cuidado inseparáveis:

Tomada em sentido verbal, vida, segundo seu sentido relacional, deve ser interpretada como cuidar, cuidar por e cuidar de algo, viver cuidando de algo. Com esse caráter não se quer dizer que a vida sempre esteja às voltas com maneirismos escrupulosos. No frenesi solto, na indiferença, na estagnação - seja como for, "viver" é caracterizado por cuidar. (HEIDEGGER, 2011a, p. 103).

Se cuidar é próprio da vida, é porque faz parte de todos os acontecimentos humanos, permitindo-nos experimentar o mundo enquanto tomamos a tarefa de encontrar um sentido para nosso ser e construímos nossas condições de vida. E isso só é possível pela estrutura da intencionalidade. A existência se projeta para além de si mesma em direção aos entes, à realidade e às suas possibilidades. $\mathrm{O}$ cuidado é um vínculo com o ser, uma experiência inseparável da vida e até mesmo lhe atribui significado. Toda tentativa de encontro com o ser é um ato intencional, uma vez que, quando nos direcionamos a algo, também estamos em busca de interrogar sobre a coisa mesma em seu modo de ser. A intencionalidade é substancial porque ela caracteriza o momento em que o Dasein sai de si mesmo em busca de algum conhecimento válido.

Portanto, a fenomenologia heideggeriana não realiza uma epoché, visto que só apreendemos os entes a partir do nosso comportamento no mundo cotidiano, prático e significativo. Com a redução eidética, a própria realidade histórica é dispensada de julgamento em nossas atividades e a consciência se transforma em uma evidência. Por seu turno, Heidegger descobriu na historicidade o âmbito que 
constitui uma base indispensável para conhecermos algo, visto que partir da vida fática permite que as coisas mesmas apareçam na região aberta a possibilidades, acontecimentos e modificações histórico-temporais. E essa postura só é possível através do cuidado e quando deixamos que o ser se manifeste sem representações.

Para Borges-Duarte (2010, p. 122), "O cuidado é o como do próprio dar-se do ser no seu (ao seu) aí: o seu aparecer na compreensão afectiva do Dasein, já originariamente articulada num comportamento que se expressa em palavra e acto", mas que também abarca nossas experiências concretas e o fazer no dia a dia. Se todos nós possuímos a intencionalidade, nossas ações jamais estão vazias de sentido e conteúdo. Isso prova que existimos no mundo e com os outros, que estamos cercados por entes e somos afetados por eventos históricos. E uma vez que estamos sempre na busca de compreensão do ser, o cuidado projeta todas as nossas expectativas e ainda permite o deixar ser, o qual possibilita nosso envolvimento afetivo com os fenômenos se sobrepor ao simples dirigir-se às coisas mesmas.

\section{CONSIDERAÇÕES FINAIS}

A partir de um estudo das considerações feitas por Heidegger, fica evidente que a intencionalidade é uma estrutura essencialmente humana. No entanto, apesar deste ponto em comum com o termo em sua tradição, o pensador alemão se distancia dos seus predecessores. Husserl não se interessava pelo ser, mas pelos fenômenos e pelas coisas mesmas sob a perspectiva da consciência, apesar de ter ido além do psicologismo. Por seu turno, a fenomenologia heideggeriana é hermenêutica, visto que se interessa pelas coisas mesmas tais como aparecem e isso exige interpretá-las em seus modos de ser. A intencionalidade aparece porque sempre nos relacionamos com entes disponíveis, úteis e simplesmente dados que se mostram para nós e que, por fazerem parte do mundo, nunca são desprovidos de algum sentido; eles são fenômenos.

Falar em intencionalidade é resgatar um conceito basilar para a compreensão do nosso ser e trazer à discussão essa estrutura que muitas vezes fica esquecida, ainda que esteja sempre em movimento. De maneira semelhante, é o cuidado que, segundo Heidegger, sustenta a existência. O cuidar move todas as reflexões, ações e o próprio viver humano de todos os dias. E a intencionalidade pertence ao Dasein em vez de se constituir como uma categoria do sujeito transcendental. No lugar de uma ciência rigorosa, surge um caminho que propõe o entendimento histórico e temporal dos fenômenos, do mundo e de nós mesmos, cujo sentido seria atribuído pelo pertencimento ao mundo e pelo cuidado em deixar o ser se manifestar. A intencionalidade é o "dirigir-se" para os fenômenos, os eventos e os outros, para nossas ideias e a vida cotidiana.

Mesmo que sejamos incapazes de percebê-la, seu trabalho é incessante e um pressuposto da existência humana. Se entendermos que toda consciência é consciência de algo, finalmente seremos capazes de aprender que nossas ações têm uma direção e que todo ente ocupa um lugar nessa totalidade chamada de mundo da vida (Lebenswelt). Mas é apenas com o exercício de cuidar que nossas 
relações com as coisas mesmas adquirem sentido, tal como buscado com tanta dedicação pela filosofia. Afinal, não seria a fenomenologia hermenêutica o método próprio do filosofar, já que sempre nos voltamos para as coisas mesmas com o propósito de desvelar sua essência? E, por isso mesmo, a intencionalidade é a própria estrutura que nos move enquanto entes concretos, atuantes e pensantes.

\section{REFERÊNCIAS}

BORGES-DUARTE, Irene. A fecundidade ontológica da noção de cuidado. De Heidegger a Maria de Lourdes Pintasilgo. Ex Aequo (Oeiras), v. 21, p. 115-131, 2010.

Husserl e a fenomenologia heideggeriana da fenomenologia. Phainomenon: revista de fenomenologia, v.7, Lisboa, p. 87-103, 2003.

CABRAL, Michelle Silvestre. A noção husserliana de consciência intencional e suas origens", Intuitio (Porto Alegre), v. 3, p. 120-138, 2010.

CROWELL, Steven. Ser respondível: A apresentação de razões e o sentido ontológico do discurso. In: CROWELL, Steven; MALPAS, Jeff. Heidegger e a tarefa da filosofia: escritos sobre ética e fenomenologia. Tradução de Paulo Cesar Gil Ferreira. Rio de Janeiro: Via Verita, 2012.

DESCARTES, René. Discurso do método. Tradução de Maria Ermantina Galvão. 2a edição. 3aㅡ tiragem. São Paulo: Martins Fontes, 2001.

Meditações metafísicas. In: Os pensadores. Tradução de Jacob Guinsburg e Bento Prado Júnior. São Paulo: Nova Cultural, 1987.

HEIDEGGER, Martin. Interpretações fenomenológicas sobre Aristóteles: introdução à pesquisa fenomenológica. Tradução de Enio Paulo Giachini. Petrópolis: Vozes, 2011a.

Logos (Heráclito, fragment 50). In: Ensaios e conferências. Tradução de Emmanuel Carneiro Leão. 7ª edição. Petrópolis: Vozes. Bragança Paulista: Editora Universitária São Francisco, 2006.

Meu caminho para a fenomenologia. In: Sobre a questão do pensamento. Tradução de Ernildo Stein. Petrópolis: Vozes, 2009.

. Ontologia: hermenêutica da faticidade. Tradução de Márcia Sá Cavalcante Schuback. Petrópolis: Vozes, 2011 b.

Prolegomena zur Geschichte des Zeitbegriffs. Frankfurt am Main: Vittorio Klostermann, 1979.

Ser e tempo. Tradução e organização de Fausto Castilho. Campinas: Editora Unicamp; Petrópolis: Vozes, 2012.

HUSSERL, Edmund. A crise da humanidade europeia e a filosofia. Introdução e tradução de Urbano Zilles. 2a ed. Porto Alegre: EdiPucrs, 2002. 
HUSSERL, Edmund. Cartesian meditations: an introduction to phenomenology. Translated by Dorion Cairns. Netherlands: SPRINGER-SCIENCE+BUSINESS MEDIA, B.V., 1960.

Ideias para uma fenomenologia pura e para uma filosofia fenomenológica. Tradução de Márcio Suzuki. Aparecida: Ideias \& Letras, 2006.

LECLERC, André. Intencionalidade. In: BRANQUINHO, João; SANTOS, Ricardo Santos. (org.). Compêndio em Linha de Problemas de Filosofia Analítica. 1a ed. Lisboa: Centro de Filosofia da Universidade de Lisboa, v. 1. 2015. p. 1-25.

MARIANI, Emanuele. Breve história da intencionalidade. Continuidade e rupturas a partir de Husserl. In: BORGES-DUARTE, Irene; SYLLA, Bernhard (org.). Intencionalidade e cuidado. Herança e repercussão da fenomenologia. Rio de Janeiro: Via verita, 2017. p. 17-29.

PASQUALIN, Chiara. Uma releitura do cuidado heideggeriano a partir do primado ontológico da afetividade. Ekstasis: Revista de hermenêutica e fenomenologia, v.5, n.1, p. 34-60, 2016.

STEIN, Edith. O que é fenomenologia? Tradução de Ursula Anne Matthias. Argumentos: Revista de Filosofia, ano 10, n. 20, p. 215-219, jul.-dez 2018. [Título original: Was ist phänomenologie? (1924). In: ESGA (Edith Stein Gesamtausgabe), v. 9, texto 5, p. 85-90.]

ZAHAVI, Dan. A fenomenologia de Husserl. Tradução de Marco Antonio Casanova. $1^{\underline{a}}$ ed. Rio de Janeiro: Via Verita, 2015.

Recebido em: 04-07-2019

Aceito para publicação em: 12-12-19 